\title{
What we know, what we do not know, and where are we heading? Efficacy and acceptability of psychological interventions for depression
}

\author{
N. Solomonov* and J. P. Barber \\ Derner Institute of Advanced Psychological Studies, Adelphi University, Garden City, 1 South Avenue, NY, USA
}

\begin{abstract}
In the past several decades, increasing evidence supports the efficacy of psychotherapies for depression. The vast majority of findings from meta-analyses, randomized clinical trials (RCTs) and naturalistic studies have demonstrated that well-established psychotherapies (behavioural activation, problem-solving therapy, psychodynamic therapy, cognitive-behavioural therapy, interpersonal therapy and emotion-focused therapy) are superior to no-treatment and control conditions, and are in most cases equally effective in treating depression. However, despite this abundant support for psychotherapies, studies have also consistently shown high drop-out rates, high percentages of non-respondent patients who experience treatment failures, and mixed findings regarding the enduring effects of psychotherapy. Thus, there is a need to develop more personalised treatment models tailored to patients' needs. A new integrative sequential stepwise approach to the treatment of depression is suggested.
\end{abstract}

Received 27 July 2015; Accepted 27 August 2015; First published online 28 September 2015

Key words: Behaviour therapy, cognitive therapy, depression, evidence-based psychiatry, psychoanalysis and psychodynamic therapies.

\section{What do we know about the efficacy of psychotherapies for depression?}

Depression is a pervasive mental condition which interferes with all domains of one's functioning and it is one of the most common problems leading people to seek treatment (e.g. Summers \& Barber, 2010). Recent studies have shown that the approximated cumulative incidence of depression diagnosis from childhood to adulthood is between 32.54 and $51 \%$ (Rohde et al. 2012; Angst et al. 2015).

In the past several decades, over 400 randomised clinical trials have investigated the efficacy of psychotherapy for depression (Cuijpers, 2015). Despite the heated debate regarding the superiority of one treatment over others, there is fairly wide acceptance of the 'Dodo Bird Verdict' (Luborsky et al. 1975), at least in the case of depression, suggesting that all treatments are more or less equally effective (Cuijpers et al. 2008; Barth et al. 2013). Furthermore, research in the past two decades has taught us that psychotherapeutic treatments of depression are superior to waitlist and other control conditions (Barth et al. 2013; Lambert, 2013), and that psychotherapy combined

* Address for correspondence: N. Solomonov, Derner Institute of Advanced Psychological Studies, Adelphi University, Garden City, 1 South Avenue, NY, USA.

(Email: nilida1@gmail.com) with anti-depressant medication is more effective than medication alone (Barber et al. 2013; Köhler et al. 2013; Hollon et al. 2014; Fonagy, 2015; Leichsenring et al. 2015). There is also evidence suggesting that some types of psychotherapies are not only as effective as medication, but also have higher long-term enduring effects (Hollon \& Ponniah, 2010; Cuijpers et al. 2013b). We begin by briefly reviewing some of the major findings that have arisen from the literature on treatments of depression, focusing only on the best-known and more widely researched.

\section{Behavioural activation (BA)}

BA is one of the most accepted and widely used behavioural treatments. Meta analyses found BA to be as effective as cognitive-behavioural therapy, and superior to control conditions (Cuijpers et al. 2007; Mazzucchelli et al. 2009) and to medication (Ekers et al. 2014). Dimidjian et al. (2006) also showed that BA was superior to cognitive therapy and as effective as medication.

\section{Problem-solving therapy (PST)}

PST is a cognitive-behavioural treatment which emerged from behaviour modification research (D'Zurilla \& Goldfried, 1971; Nezu et al. 1989). PTS was found to 
be superior to medication and as effective as other alternative psychosocial therapies and medication (Bell \& D'Zurilla, 2009). However, another meta-analysis showed that the effects of PST vary across studies, ranging from close to zero to very large effects (Cuijpers et al. 2007).

\section{Short-term dynamic psychotherapy (STDP)}

STDP emerged from the work of Malan (1976), Mann (1973), Sifneos (1979), Davanloo (1980) and Luborsky (1984). Randomized clinical trials (RCTs) and metaanalyses have shown that STDP is as effective as medication (Barber et al. 2012), more effective than control conditions, and as effective as alternative treatments at termination and follow-up assessments (Driessen et al. 2010, 2013, 2015a, b. Gibbons et al. 2012; Abbass et al. 2014; Fonagy, 2015; Leichsenring et al. 2015). Furthermore, combined treatment of STDP and medication was found to be more effective than medication alone (Barber et al. 2013; Fonagy, 2015; Leichsenring et al. 2015).

\section{Long-term dynamic psychotherapy (LTDP)}

There is evidence supporting the effectiveness of LTDP and psychoanalysis (de Maat et al. 2009), especially in long-term follow-ups (Knekt et al. 2008, 2011; Huber et al. 2013). There is also some indirect evidence that LTDP is superior to other psychotherapies in treating complex patients with chronic depression and previous treatment failures (Leichsenring \& Rabung, 2008, 2010; Fonagy et al. in press). However, some of these conclusions have been challenged (e.g. Smit et al. 2012).

\section{Cognitive-behavioral therapy (CBT)}

CBT, pioneered by Beck et al. (1979), became the most widely studied treatment for depression. Robust evidence supports its superiority over control conditions (DeRubeis et al. 2005; Tolin, 2010; Cuijpers et al. 2013a; Marcus et al. 2014), and some studies found that combined treatment is superior to medication alone (Cuijpers et al. 2013a; Köhler et al. 2013; Hollon et al. 2014). When comparing CBT to alternative treatments, there are mixed findings (Hofmann et al. 2012). While some meta-analyses reported the superiority of CBT (e.g., Tolin, 2010; Marcus et al. 2014), they have been criticised (Leichsenring \& Rabung, 2010; Baardseth et al. 2013), and others found that it is as effective as alternative treatments (e.g. Leichsenring, 2001; Cuijpers et al. 2008, 2013a; Beltman et al. 2010; Driessen et al. 2013, 2015b).

\section{Interpersonal therapy (IPT)}

Interpersonal psychotherapy (IPT) emerged from Sullivan's (1953) interpersonal theory and was later adapted for depression (Klerman et al. 1984). In a large RCT, Elkin et al. (1989) found that IPT is equally effective to medication and CBT, with some evidence for increased efficacy of IPT for severely depressed patients. There is also preliminary evidence suggesting the superiority of IPT over alternative psychotherapies (Cuijpers et al. 2008, 2011), specifically supportive counselling (Barth et al. 2013) and CBT (de Mello et al. 2005).

\section{Emotion-focused therapy (EFT)}

EFT emerged from the humanistic, experiential and client-centred therapeutic approaches (Greenberg \& Watson, 2006). Experiential therapies were found slightly more effective than non-treatment and control conditions ( $\mathrm{ES}=0.12$; Elliott et al. 2004); however, effects largely varied in magnitude and direction. Studies found that adding emotion-focused techniques to client-centred therapy increased the efficacy of treatment (Greenberg \& Watson, 1998; Goldman et al. 2006), and that EFT was superior to client-centred therapy in long-term follow-ups (Ellison et al. 2009). Watson et al. (2003) found in an RCT that EFT equal to CBT but superior in reduction of interpersonal problems. Overall, while preliminary evidence supports the efficacy of EFT, there is still a need for future research comparing EFT to placebo, control and alternative psychotherapies.

\section{Strengths and weaknesses of meta-analyses}

In this paper, we base many of our arguments on data from meta-analyses. While meta-analyses are an important source of information, providing reviews and summaries of large numbers of studies, we are also aware of their limitations. Specifically, the quality of a meta-analysis derives in part from the quality and thoroughness of the studies included in it. Considering quality in determining the conclusion from a meta-analysis is not a simple proposition (Kocsis et al. 2010; Gerber et al. 2011; Thoma et al. 2012). One can include study quality as a moderator in one's meta-analysis, as some researchers have done; however, this is not common practice and may reflect the authors' biases. More specifically, if a meta-analysis is not all-inclusive, it may be biased in one direction and could suffer from the author's 'allegiance' (see Leichsenring \& Rabung, 2010; Baardseth et al. 2013). Thus, taking those limitations into account, we surmise that meta-analyses provide a rich and valuable source 
of information, although the specifics require close scrutiny. One important question for the field is whether to prefer the results of a meta-analysis which includes several average quality studies to those of several high-quality trustworthy specific RCTs which suggests the superiority of treatment A over a control condition (Hollon, personal communication, 2015).

What we still do not know about treatment of depression: remission and drop-out rates, enduring effects and treatment-resistant forms of depression

\section{Remission rates}

The ultimate goal of all treatments of depression is remission. It is often thought that if a treatment was given in an appropriate dose and duration and it did not end with remission, it cannot be considered successful (John Rush et al. 2006; Hollon et al. 2014). However, in depression, it is possible for response and remission to occur without treatment with estimated high rates of spontaneous remission ranging from $23 \%$ within 3 months to $53 \%$ within 12 months (Whiteford et al. 2013). Therefore, efficacious treatments are expected to result in significantly higher remission rates and/or a much quicker recovery time.

Despite the well-established benefits of treating depression over no treatment, findings from RCTs and naturalistic studies show that remission rates are far from $100 \%$ across all treatment modalities. Specifically, one of the largest RCTs (STAR*D), which tested the efficacy of sequential treatment allocation of medication and cognitive therapy, reported an overall remission rate of $27.5-32.9 \%$ (Trivedi et al. 2006), with decreasing rates from $32.9 \%$ in step 1 to $14.7 \%$ in step 4 (John Rush et al. 2006). These findings clearly call for a need to improve our treatment modalities.

In fact, in face of the low remission rates, NIMH director Insel $(2009,2006)$, emphasised a pressing need to develop new approaches to diagnosing and treating depression. As a result, most NIMH funding resources have shifted towards researching new neurobiologically based approaches to mental illnesses using NIMH's new diagnostic system - the Research Domain Criteria (RDoC) (e.g. Cuthbert \& Insel, 2013). In the context of treating depression, the $\mathrm{NIMH}$ has been moving towards the development of personalised interventions based on the specific needs and circumstances of each individual patient.

\section{Drop-out rates}

Premature discontinuation, also referred to as dropout, is a major concern as it impedes the effectiveness of treating depression (Cahill et al. 2003). While dropout rates vary, premature discontinuation is a problem shared by all psychotherapies. A recent meta-analysis found a mean rate of $17.5 \%$ dropout in therapies for depression, with a large variance across studies ranging between 0 and 50\% (Cooper \& Conklin, 2015). Another meta-analysis (Flückiger et al. 2014) found $29.2 \%$ drop-out rate in evidence-based treatments (EBT) for acute depression and anxiety disorders (compared with $32.7 \%$ rate in treatment-as-usual control conditions (TAU)). Meta-analyses comparing dropout rates in different psychotherapies have yielded mixed findings, from equal dropout rates across treatments (Cooper \& Conklin, 2015), to significant differences between psychotherapies, with the highest rate in CBT and the lowest rate in PST (Cuijpers et al. 2008). Taken together, these findings demonstrate the strong need to develop new treatment models tailored to patients' needs.

\section{Enduring effects of psychotherapy}

While ample evidence supports the efficacy of psychotherapies for depression at the endpoint of treatment, much less is known about their enduring effects. Some researchers found that different psychotherapies are effective in preventing relapse/recurrence (Hollon et al. 2006; Hollon \& Ponniah, 2010; Steinert et al. 2014; Biesheuvel-Leliefeld et al. 2015) and that their enduring effects are as effective as a continuous use of medications (Cuijpers et al. 2013b). In contrast, others have shown that the superiority of EBT for acute depression and anxiety disorders over TAU is minimal on $0-4$-month follow-ups, and does not extend at 8-12-month follow-ups (Flückiger et al. 2014).

These mixed findings indicate the need to study the long-term effects of psychotherapy (Lambert, 2013). The lack of evidence may largely be due to the major limitations of follow-up research. First, in some countries, there is no detailed information about patients' treatment utilisation and researchers need to rely on self-reports, which are often biased. Second, patients' frequent reluctance to participate in follow-ups often results in a large amount of missing data.

\section{Treatment resistant depression}

Accumulating evidence has shown that depression is a pervasive and chronic disorder and that many patients do not benefit from standard treatments. Researchers have identified a $43 \%$ recurrence of episodes among depressed young adults and $5-19 \%$ of suicide attempts among depressed patients aged 5-30 (Rohde et al. 2012). These findings have led investigators to focus 
on 'treatment-resistant' forms of depression (Taylor et al. 2012). Studies attempting to identify patient characteristics, which are more highly correlated with - or predictive of - high dropout rates and/or poorer outcome, have resulted in mixed findings. Some researchers found comorbidity of personality disorders and social racial minority status to be predictive of higher dropout rates (Cooper \& Conklin, 2015). Others reported that these characteristics did not moderate the superiority of EBT over TAU, but rather identified additional moderators such as comorbidity of substance abuse (Flückiger et al. 2014). These contrasting findings demonstrate the need to develop more effective ways to treat non-responders (Barrett et al. 2008).

\section{Where are we heading?}

\section{A suggestion for an alternative stepwise sequential model of allocation of treatment for depression}

This paper reviewed the significant progress in the development and research of EBT for depression in the past few decades. However, evidence of high dropout rates, large non-responsive populations and mixed findings regarding the enduring effects of psychotherapy suggest that there is still much to be learned about the treatment of depression.

We believe that there is a need to develop a stepwise sequential approach for a more cost-effective and applicable treatment modalities that will integrate different evidence-based therapies while taking into account patients' characteristics and needs. Similar to treatment modalities in advanced individualised medicine, we encourage clinicians to use their clinical judgment and to make decisions based on sessionto-session feedback and continuous awareness of the patient's progress. Medication can be incorporated into each phase of treatment; however, this is not the focus of our model at this point. Our suggestion is preliminary, stating that more research needs to be done in order to determine the specific use of medication (see Fig. 1 for the outline of the model).

Step 1: BA or PST. The treatment process should begin with a time-limited focused therapy such as BA or PST. Since these treatments are brief, costeffective and have proven to be successful for large depressed populations, it would be reasonable to use them as a first line of treatment.

Step 2: CBT, IPT, EFT or STDP: In case of nonresponse, we suggest moving to the second phase short-term treatments: CBT, IPT, EPT or STDP. Given the evidence from RCTs and meta-analyses, we believe that there is a great likelihood that these treatments will be equally effective and appropriate for patients who have failed to improve in briefer and more

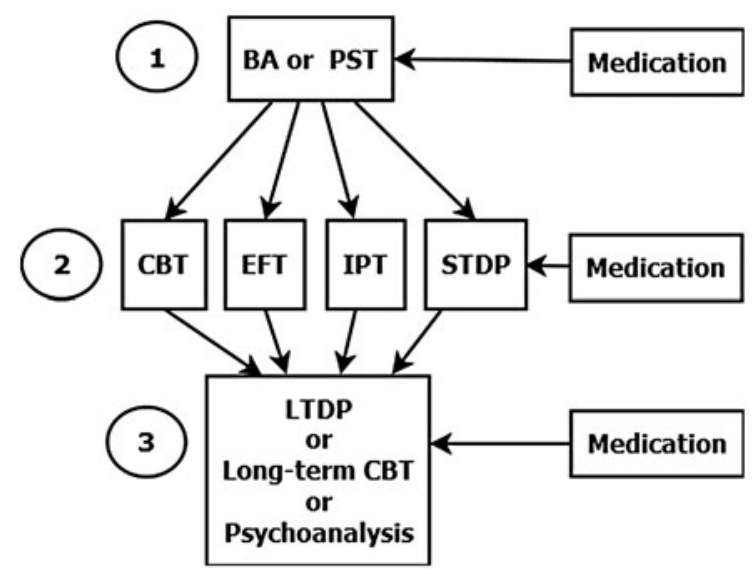

Fig. 1. A suggestion for an integrative stepwise sequential model for treatment of depression. Note: BA, behavioural activation therapy; PST, problem-solving therapy; CBT, cognitive-behavioural therapy; IPT, interpersonal therapy; EFT, emotion focused therapy; STDP, short-term dynamic psychotherapy; LTDP, long-term dynamic psychotherapy.

symptom-focused treatments. There is, however, some evidence that specific subgroups of patients benefit more from specific treatments (Barber \& Muenz, 1996; Sotsky et al. 2006; Barber et al. 2012; Beutler et al. 2012; DeRubeis et al. 2014). If replicated, these findings should be included in the model.

Step 3: LTDP or Long-term CBT: Complex patients, who suffer from chronic depression and have shown two treatment failures in steps 1 and 2, will be referred to long-term CBT or LTDP. This suggestion is based on the promising evidence supporting the efficacy of LTDP for complex patients who experienced treatment failures and impressive RCT findings showing high remission rates $(80.1 \%)$ after 18 months of combined therapy (cognitive therapy + medication) (Hollon et al. 2014).

\section{Important considerations}

The suggested model should be adjusted according to the therapist's clinical judgment, the patient's preferences and progress and the limitations of the clinical settings (such as the availability of therapists from a specific approach). Additionally, we expect that computer-based treatments will be included in this model in the future, given the increasing evidence supporting their efficacy and their advantages (high costeffectiveness and high accessibility to a range of populations).

Lastly, we expect that future adjustments will be applied to the model based on the accumulating evidence on moderators and predictors of treatment success. Some preliminary findings have shown that 
specific populations benefit from specific treatments (e.g., Barber \& Muenz, 1996; Sotsky et al. 2006; DeRubeis et al. 2014). For example, Barber et al. (2012) found that depressed minority men (mostly AfricanAmerican) benefited more from short-term supportiveexpressive therapy than placebo or medication. We recommend that future studies focus on replicating these previous findings and identifying more significant factors affecting treatment success.

\section{Summary and concluding remarks}

So what do we know? We know that there is a fairly wide range of effective psychotherapies. We also know that these treatments are probably more or less equally effective and that they are better than no-treatment or other control conditions. However, we still do not know why these treatments are often ineffective or only partially effective for many patients. We do not know why so many depressed patients choose to drop out of treatment. We also do not know why in many cases patients who have shown partial or full remission experience relapse. Given what we know and what we still do not know, we suggest a possible alternative model, incorporating EBT, while taking into account patients' specific needs and circumstances.

We acknowledge that while our model may be useful and applicable to Western countries, it might not be as relevant to individuals in third world countries, or even those who reside in remote areas of Western countries who lack access to services and/or the financial resources needed. That being said, we also predict that as the effects of globalisation increase and many countries become more developed, the demand for treatments of depression will drastically increase. Thus, there is a need for researchers to break through the boarders of their own countries (especially in the USA and Europe, where most researchers are located) and develop more rigorous and extensive research focusing on treatments that could be applicable for larger and more diverse populations world-wide.

With a lack of availability of treatments in remote areas and in less developed countries, depressed patients are more and more likely to be prescribed medication, especially as many SSRIs have become generic, without ever being offered psychotherapy. Our concern is that while medication can be as effective as and cheaper than therapy, it does not teach the patient anything (e.g. Barber \& DeRubeis, 1989). It does not help the patient to gain insight and self-understanding, reflect on emotional states, challenge thoughts and beliefs, develop more adaptive coping skills and behaviours, improve self-esteem and make changes in interpersonal relationships.
While we acknowledge that the future goals of psychotherapy research are challenging and ambitious, we believe that the ever-growing productivity of psychotherapy researchers around the world and the increasing interest of young students and professionals in the field of psychotherapy can indicate that our field will continue to be fruitful and successful in decades to come.

\section{Acknowledgement}

We would like to thank Mark Blanchard for his valuable assistance in preparation of this manuscript.

\section{Financial support}

This research received no specific grant from any funding agency, commercial or not-for-profit sectors.

\section{Conflict of Interest}

None.

\section{References}

Abbass AA, Kisely SR, Town JM, Leichsenring F, Driessen E, De Maat S, Gerber A, Dekker J, Rabung S, Rusalovska S, Crowe E (2014). Short-term psychodynamic psychotherapies for common mental disorders. Cochrane Database Systematic Review 7. doi: 10.1002/14651858. CD004687.pub4.

Angst J, Paksarian D, Cui L, Merikangas KR, Hengartner MP, Ajdacic-Gross V, Rössler W (2015). The epidemiology of common mental disorders from age 20 to 50: results from the prospective Zurich cohort Study. Epidemiology and Psychiatric Sciences, Advanced online publication. doi: 10.1017/S204579601500027X.

Baardseth TP, Goldberg SB, Pace BT, Wislocki AP, Frost ND, Siddiqui JR, Wampold BE (2013).

Cognitive-behavioral therapy versus other therapies: redux. Clinical Psychology Review 33, 395-405.

Barber JP, DeRubeis RJ (1989). On second thought: where the action is in cognitive therapy for depression. Cognitive Therapy and Research 13, 441-457.

Barber JP, Muenz LR (1996). The role of avoidance and obsessiveness in matching patients to cognitive and interpersonal psychotherapy: empirical findings from the treatment for Depression Collaborative Research Program. Journal of Consulting and Clinical Psychology 64, 951-958.

Barber JP, Barrett MS, Gallop R, Rynn MA, Rickels K (2012). Short-term dynamic psychotherapy versus pharmacotherapy for major depressive disorder: a randomized, placebo-controlled trial. Journal of Clinical Psychiatry 73, 66-73.

Barber JP, Muran JC, McCarthy KS, Keefe JR (2013). Research on dynamic therapies. In Bergin and Garfield's Handbook of Psychotherapy and Behavior Change, 6th edn. (ed. MJ Lambert), pp. 443-494. Wiley: Hoboken, NJ. 
Barrett MS, Chua W-J, Crits-Christoph P, Gibbons MB, Thompson D (2008). Early withdrawal from mental health treatment: implications for psychotherapy practice. Psychotherapy: Theory, Research, Practice, Training 45, 247-267.

Barth J, Munder T, Gerger H, Nüesch E, Trelle S, Znoj H, Jüni P, Cuijpers P (2013). Comparative efficacy of seven psychotherapeutic interventions for patients with depression: a network meta-analysis. PLoS Medicine 10, 1-17.

Beck AT, Rush AJ, Shaw BF, Emery G (1979). Cognitive Therapy of Depression. New York: Guilford.

Bell AC, D'Zurilla TJ (2009). Problem-solving therapy for depression: a meta-analysis. Clinical Psychology Review 29, 348-353.

Beltman MW, Voshaar RCO, Speckens AE (2010). Cognitive-behavioural therapy for depression in people with a somatic disease: meta-analysis of randomised controlled trials. British Journal of Psychiatry 197, 11-19.

Beutler LE, Forrester B, Gallagher-Thompson D, Thompson L, Tomlins JB (2012). Common, specific, and treatment fit variables in psychotherapy outcome. Journal of Psychotherapy Integration 22, 255-281.

Biesheuvel-Leliefeld KE, Kok GD, Bockting CL, Cuijpers P, Hollon SD, van Marwijk HW, Smit F (2015). Effectiveness of psychological interventions in preventing recurrence of depressive disorder: meta-analysis and meta-regression. Journal of Affective Disorders 174, 400-410.

Cahill J, Barkham M, Hardy G, Rees A, Shapiro DA, Stiles WB, Macaskill N (2003). Outcomes of patients completing and not completing cognitive therapy for depression. British Journal of Clinical Psychology 42, 133-143.

Cooper AA, Conklin LR (2015). Dropout from individual psychotherapy for major depression: a meta-analysis of randomized clinical trials. Clinical Psychology Review 40, 57-65.

Cuijpers P (2015). Psychotherapies for adult depression: recent developments. Current Opinion in Psychiatry 28, 24-29.

Cuijpers P, Van Straten A, Warmerdam L (2007). Behavioral activation treatments of depression: a meta-analysis. Clinical Psychology Review 27, 318-326.

Cuijpers P, Van Straten A, Andersson G, Van Oppen P (2008). Psychotherapy for depression in adults: a meta-analysis of comparative outcome studies. Journal of Consulting and Clinical Psychology 76, 909-922.

Cuijpers P, Geraedts AS, van Oppen P, Andersson G, Markowitz JC, van Straten A (2011). Interpersonal psychotherapy for depression: a meta-analysis. American Journal of Psychiatry 168, 581-592.

Cuijpers P, Berking M, Andersson G, Quigley L, Kleiboer A, Dobson KS (2013a). A meta-analysis of cognitive-behavioural therapy for adult depression, alone and in comparison with other treatments. Canadian Journal of Psychiatry 58, 376-385.

Cuijpers P, Hollon SD, van Straten A, Bockting C, Berking M, Andersson G (2013b). Does cognitive behaviour therapy have an enduring effect that is superior to keeping patients on continuation pharmacotherapy? A meta-analysis. BMJ Open 3, 1-8.

Cuthbert BN, Insel TR (2013). Toward the future of psychiatric diagnosis: the seven pillars of RDoC. BMC Medicine 11, 126.
Davanloo H (ed.) (1980). Short-term Dynamic Psychotherapy. Jason Aranson: New York, NY.

de Maat S, de Jonghe F, Schoevers R, Dekker J (2009). The effectiveness of long-term psychoanalytic therapy: a systematic review of empirical studies. Harvard Review of Psychiatry 17, 1-23.

de Mello MF, de Jesus Mari J, Bacaltchuk J, Verdeli H, Neugebauer R (2005). A systematic review of research findings on the efficacy of interpersonal therapy for depressive disorders. European Archives of Psychiatry and Clinical Neuroscience 255, 75-82.

DeRubeis RJ, Cohen ZD, Forand NR, Fournier JC, Gelfand LA, Lorenzo-Luaces L (2014). The personalized advantage index: translating research on prediction into individualized treatment recommendations. A demonstration. PLoS ONE 9, e83875.

DeRubeis RJ, Hollon SD, Amsterdam JD, Shelton RC, Young PR, Salomon RM, O'Reardon JP, Lovett ML, Gladis MM, Brown LL, Gallop R (2005). Cognitive therapy vs medications in the treatment of moderate to severe depression. Archives of General Psychiatry 62, 409-416.

Dimidjian S, Hollon SD, Dobson KS, Schmaling KB, Kohlenberg RJ, Addis ME, Jacobson NS (2006). Randomized trial of behavioral activation, cognitive therapy, and antidepressant medication in the acute treatment of adults with major depression. Journal of Consulting and Clinical Psychology 74, 658-670.

Driessen E, Cuijpers P, de Maat SC, Abbass AA, de Jonghe F, Dekker JJ (2010). The efficacy of short-term psychodynamic psychotherapy for depression: a meta-analysis. Clinical Psychology Review 30, 25-36.

Driessen E, Van HL, Don FJ, Peen J, Kool S, Westra D, Dekker JJ (2013). The efficacy of cognitive-behavioral therapy and psychodynamic therapy in the outpatient treatment of major depression: a randomized clinical trial. American Journal of Psychiatry 170, 1041-1050. Retrieved from http://search.proquest.com/docview/1440252902? accountid=8204.

Driessen E, Hegelmaier LM, Abbass AA, Barber JP, Dekker JJ, Van HL, Cuijpers P (2015a). The efficacy of short-term psychodynamic psychotherapy for depression: a meta-analysis update. Clinical Psychology Review 42, 1-15.

Driessen E, Van HL, Peen J, Don FJ, Kool S, Westra D, Dekker JJ (2015b). Therapist-rated outcomes in a randomized clinical trial comparing cognitive behavioral therapy and psychodynamic therapy for major depression. Journal of Affective Disorders 170, 112-118.

D'Zurilla TJ, Goldfried MR (1971). Problem solving and behavior modification. Journal of Abnormal Psychology 78, 107-126.

Ekers D, Webster L, Van Straten A, Cuijpers P, Richards D, Gilbody S (2014). Behavioural activation for depression; an update of meta-analysis of effectiveness and sub group analysis. PLOS ONE 9, e100100.

Elkin I, Shea MT, Watkins JT, Imber SD, Sotsky SM, Collins JF, Parloff MB (1989). National Institute of Mental Health treatment of depression collaborative research program: general effectiveness of treatments. Archives of General Psychiatry 46, 971-982. 
Elliott R, Greenberg LS, Lietaer G (2004). Research on experiential psychotherapies. In Bergin \& Garfield's Handbook of Psychotherapy and Behavior Change, 5th edn (ed. MJ Lambert), pp. 493-539. Wiley: New York.

Ellis AE (1962). Reason and Emotion in Psychotherapy. Lyle Stuart: New York.

Ellison J, Greenberg L, Goldman R, Angus L (2009). Maintenance of gains at follow-up in experiential therapies for depression. Journal of Consulting and Clinical Psychology 77, 103-112.

Flückiger C, Del Re AC, Munder T, Heer S, Wampold BE (2014). Enduring effects of evidence-based psychotherapies in acute depression and anxiety disorders versus treatment as usual at follow-up - a longitudinal meta-analysis. Clinical Psychology Review 34, 367-375.

Fonagy P (2015). The effectiveness of psychodynamic psychotherapies: an update. World Psychiatry 14, 137-150.

Fonagy P, Rost F, Carlyle J et al. (in press). Randomized controlled trial of long-term psychoanalytic psychotherapy for chronic 'treatment resistant/treatment-refractory' depression: the Tavistock Adult Depression Study (TADS). World Psychiatry.

Gerber AJ, Kocsis JH, Milrod BL, Roose SP, Barber JP, Thase ME, Leon AC (2011). A quality-based review of randomized controlled trials of psychodynamic psychotherapy. Perspectives 168, 19-28.

Gibbons MBC, Thompson SM, Scott K, Schauble LA, Mooney T, Thompson D, Crits-Christoph P (2012). Supportive-expressive dynamic psychotherapy in the community mental health system: a pilot effectiveness trial for the treatment of depression. Psychotherapy 49, 303-316.

Goldman RN, Greenberg LS, Angus L (2006). The effects of adding emotion-focused interventions to the client-centered relationship conditions in the treatment of depression. Psychotherapy Research 16, 537-549.

Greenberg L, Watson J (1998). Experiential therapy of depression: differential effects of client-centered relationship conditions and process experiential interventions. Psychotherapy Research 8, 210-224.

Greenberg LS, Watson JC (2006). Emotion-focused Therapy for Depression. American Psychological Association: Washington, DC.

Hofmann SG, Asnaani A, Vonk IJJ, Sawyer AT, Fang A (2012). The efficacy of cognitive behavioral therapy: a review of meta-analyses. Cognitive Therapy and Research 36, 427-440.

Hollon SD, Ponniah K (2010). A review of empirically supported psychological therapies for mood disorders in adults. Depression and Anxiety 27, 891-932.

Hollon SD, Stewart MO, Strunk D (2006). Enduring effects for cognitive behavior therapy in the treatment of depression and anxiety. Annual Review of Psychology 57, 285-315.

Hollon SD, DeRubeis RJ, Fawcett J, Amsterdam JD, Shelton RC, Zajecka J, Gallop R (2014). Effect of cognitive therapy with antidepressant medications vs antidepressants alone on the rate of recovery in major depressive disorder: a randomized clinical trial. JAMA Psychiatry 71, 1157-1164.

Huber D, Henrich G, Clarkin J, Klug G (2013).

Psychoanalytic versus psychodynamic therapy for depression: a three-year follow-up study. Psychiatry: Interpersonal and Biological Processes 76, 132-149.

Insel TR (2006). Beyond efficacy: the STAR ${ }^{*} \mathrm{D}$ trial. American Journal of Psychiatry 163, 5-7.

Insel TR (2009). Translating scientific opportunity into public health impact: a strategic plan for research on mental illness. Archives of General Psychiatry 66, 128-133.

John Rush MD, Trivedi MH, Wisniewski SR, Nierenberg AA, Stewart JW, Warden D, Fava M (2006). Acute and longer-term outcomes in depressed outpatients requiring one or several treatment steps: a STAR* D report. American Journal of Psychiatry 163, 1905-1917. Retrieved from: ajp. psychiatryonline.org.

Klerman GL, Weissman MM, Rounsaville BJ, Chevron ES (1984). Interpersonal Psychotherapy of Depression. Basic Books: New York.

Knekt P, Lindfors $O$, Härkänen T, Välikoski M, Virtala E, Laaksonen MA, Renlund C (2008). Randomized trial on the effectiveness of long-and short-term psychodynamic psychotherapy and solution-focused therapy on psychiatric symptoms during a 3-year follow-up. Psychological Medicine 38, 689-703.

Knekt P, Lindfors O, Laaksonen MA, Renlund C, Haaramo P, Härkänen T, Helsinki Psychotherapy Study Group (2011). Quasi-experimental study on the effectiveness of psychoanalysis, long-term and short-term psychotherapy on psychiatric symptoms, work ability and functional capacity during a 5-year follow-up. Journal of Affective Disorders 132, 37-47.

Kocsis JH, Gerber AJ, Milrod B, Roose SP, Barber J, Thase ME, Leon AC (2010). A new scale for assessing the quality of randomized clinical trials of psychotherapy. Comprehensive Psychiatry 51, 319-324.

Köhler S, Hoffmann S, Unger T, Steinacher B, Dierstein N, Fydrich T (2013). Effectiveness of cognitive-behavioural therapy plus pharmacotherapy in inpatient treatment of depressive disorders. Clinical Psychology and Psychotherapy 20, 97-106.

Lambert MJ (2013). Efficacy and effectiveness of psychotherapy. In Bergin and Garfield's Handbook of Psychotherapy and Behavior Change, 6th edn. (ed. MJ Lambert), pp. 169-219. Wiley: New York.

Leichsenring F (2001). Comparative effects of short-term psychodynamic psychotherapy and cognitive-behavioral therapy in depression: a meta-analytic approach. Clinical Psychology Review 21, 401-419.

Leichsenring F, Rabung S (2008). Effectiveness of long-term psychodynamic psychotherapy: a meta-analysis. Jama 300, 1551-1565.

Leichsenring F, Rabung S (2010). Double standards in psychotherapy research. Psychotherapy and Psychosomatics 80, 48-51.

Leichsenring F, Luyten P, Hilsenroth MJ, Abbass A, Barber JP, Keefe JR, Steinert C (2015). Psychodynamic therapy meets evidence-based medicine: a systematic review using updated criteria. Lancet Psychiatry 2, 648-660.

Luborsky L (1984). Principles of Psychoanalytic Psychotherapy: A Manual for Supportive-Expressive Treatment. Basic Books: New York, NY. 
Luborsky L, Singer B, Luborsky L (1975). Comparative studies of psychotherapies: is it true that everyone has won and all must have prizes? Archives of General Psychiatry 32, 995-1008.

Malan DH (1976). Individual Psychotherapy and the Science of Psychodynamics. Butterworth: Woburn, MA.

Mann J (1973). Time Limited Psychotherapy. Harvard University: Cambridge, MA.

Marcus DK, O'Connell D, Norris AL, Sawaqdeh A (2014). Is the Dodo bird endangered in the 21st century? A meta-analysis of treatment comparison studies. Clinical Psychology Review 34, 519-530.

Mazzucchelli T, Kane R, Rees C (2009). Behavioral activation treatments for depression in adults: a meta-analysis and review. Clinical Psychology: Science and Practice 16, 383-411.

Nezu AM, Nezu CM, Perri MG (1989). Problem-solving Therapy for Depression: Theory, Research, and Clinical Guidelines. John Wiley \& Sons: Oxford, England.

Rohde P, Lewinsohn PM, Klein DN, Seeley JR, Gau JM (2012). Key characteristics of major depressive disorder occurring in childhood, adolescence, emerging adulthood, and adulthood. Clinical Psychological Science, 1-21.

Sifneos P (1979). Short-term Dynamic Psychotherapy: Evaluation and Technique. Plenum Press: New York, NY.

Smit Y, Huibers MJ, Ioannidis JP, van Dyck R, van Tilburg W, Arntz A (2012). The effectiveness of long-term psychoanalytic psychotherapy - A meta-analysis of randomized controlled trials. Clinical Psychology Review 32, 81-92.

Sotsky SM, Glass DR, Shea MT, Pilkonis PA, Collins F, Elkin I, Oliveri ME (2006). Patient predictors of response to psychotherapy and pharmacotherapy: findings in the $\mathrm{NIMH}$ treatment of depression collaborative research program. FOCUS 4, 278-290.
Steinert C, Hofmann M, Kruse J, Leichsenring F (2014). Relapse rates after psychotherapy for depression-stable long-term effects? A meta-analysis. Journal of Affective Disorders 168, 107-118.

Sullivan HS (1953). The Interpersonal Theory of Psychiatry. Norton: New York, NY.

Summers RF, Barber JP (2010). Psychodynamic Therapy: A Guide to Evidence-based Practice. Guilford Press: New York, NY.

Taylor D, Carlyle JA, McPherson S, Rost F, Thomas R, Fonagy P (2012). Tavistock Adult Depression Study (TADS): a randomised controlled trial of psychoanalytic psychotherapy for treatment-resistant/treatment-refractory forms of depression. BMC Psychiatry 12, 60-73.

Thoma NC, McKay D, Gerber AJ, Milrod BL, Edwards AR, Kocsis JH (2012). A quality-based review of randomized controlled trials of cognitive-behavioral therapy for depression: an assessment and metaregression. American Journal of Psychiatry 169, 22-30.

Tolin DF (2010). Is cognitive-behavioral therapy more effective than other therapies?: a meta-analytic review. Clinical Psychology Review 30, 710-720.

Trivedi MH, Rush AJ, Wisniewski SR, Nierenberg AA, Warden D, Ritz L, Star* D Study Team (2006). Evaluation of outcomes with citalopram for depression using measurement-based care in STAR ${ }^{*} \mathrm{D}$ : implications for clinical practice. American Journal of Psychiatry 163, 28-40.

Watson JC, Gordon LB, Stermac L, Kalogerakos F, Steckley P (2003). Comparing the effectiveness of process-experiential with cognitive-behavioral psychotherapy in the treatment of depression. Journal of Consulting and Clinical Psychology 71, 773-781.

Whiteford HA, Harris MG, McKeon G, Baxter A, Pennell C, Barendregt JJ, Wang J (2013). Estimating remission from untreated major depression: a systematic review and meta-analysis. Psychological Medicine 43, 1569-1585. 